\title{
THE
}

\section{Expanding the evolutionary explanations for sex differences in the human skeleton}

Holly M. Dunsworth

University of Rhode Island, holly_dunsworth@uri.edu

Follow this and additional works at: https://digitalcommons.uri.edu/soc_facpubs

The University of Rhode Island Faculty have made this article openly available.

Please let us know how Open Access to this research benefits you.

This is a pre-publication author manuscript of the final, published article.

Terms of Use

This article is made available under the terms and conditions applicable towards Open Access

Policy Articles, as set forth in our Terms of Use.

\section{Citation/Publisher Attribution}

Dunsworth, HM. Expanding the evolutionary explanations for sex differences in the human skeleton.

Evolutionary Anthropology. 2020; 29: 108-116. https://doi.org/10.1002/evan.21834

Available at: https://doi.org/10.1002/evan.21834

This Article is brought to you for free and open access by the Sociology \& Anthropology at DigitalCommons@URI. It has been accepted for inclusion in Sociology \& Anthropology Faculty Publications by an authorized administrator of DigitalCommons@URI.For more information, please contact digitalcommons-group@uri.edu. 


\title{
Expanding the evolutionary explanations for sex differences in the human skeleton
}

Holly M. Dunsworth

Department of Sociology and Anthropology, University of Rhode Island

Running title: Evolved sex differences in the human skeleton

October 1, 2019

\begin{abstract}
While the anatomy and physiology of human reproduction differ between the sexes, the effects of hormones on skeletal growth do not. Human bone growth depends on estrogen. Greater estrogen produced by ovaries causes bones in female bodies to fuse before males' resulting in sex differences in adult height and mass. Female pelves expand more than males' due to estrogen and relaxin produced and employed by the tissues of the pelvic region and potentially also due to greater internal space occupied by female gonads and genitals. Evolutionary explanations for skeletal sex differences (aka sexual dimorphism) that focus too narrowly on big competitive men and broad birthing women must account for the adaptive biology of skeletal growth and its dependence on the developmental physiology of reproduction. In this case, dichotomizing evolution into proximate-ultimate categories may be impeding the progress of human evolutionary science, as well as enabling the popular misunderstanding and abuse of it.
\end{abstract}

Key words: sexual dimorphism, height, growth, pelvis, estrogen, childbirth, male competition

\section{Introduction}

Scholarship on sex differences in the human skeleton, from the focused to the tangential, explains how males are taller due to sexual selection for contest winners, and how females are broader due to natural selection for childbirth. (For just two recent examples see refs 1 and 2, respectively; for textbook examples, see refs 3-5) While discourse among anthropologists and fellow travelers on skeletal sex differences is often nuanced about causal complexity and unknowns, it does not seem to have affected the discussion beyond these circles, where public perception of evolutionary causality is far simpler. The narrow emphasis on competitive men and birthing women harkens back to the origins of human evolutionary biology ${ }^{6,7}$, and these explanations for biological sex differences dominate the popular understanding of human evolution today.

Here, 'female' refers to humans of all genders with anatomy that is commonly assigned to be female, and the same gender inclusivity applies to 'male'-with the understanding that neither sex nor gender divide into uniform, discrete, or binary categories, which is why "sex differences" rather than "sexual dimorphism" is employed throughout this essay. ${ }^{8-10}$ 
This essay briefly reviews the complex biology of sex differences in human stature and pelvic dimensions, focusing mainly on the role of estrogen. Investigating how these differences develop expands their evolutionary explanations. Peering from this angle stirs skepticism of the traditional, narrow emphasis on the dominant ideas, and creates opportunities for testing them. To be clear, the reigning explanations (male competition for skeletal size differences, and childbirth for pelvic differences) are neither extensively reviewed nor rebutted in this essay. Instead, the goal of this essay is to highlight some additional context for the evolution of sex differences in the skeleton. In order to present a fresh approach to a familiar topic, this essay primarily asks why skeletal sex differences exist at all, rather than starting with comparisons of degrees of sex differences between humans and other primates.

Throughout this essay, and perhaps already by now, many readers will be partitioning evidence into the dichotomous realms of proximate and ultimate evolutionary explanations ${ }^{11}$ - the ultimate ones being childbirth and male competition and the proximate ones being mechanisms of growth and development of the skeleton. However, this convention is not a requirement of evolutionary thinking ${ }^{12}$ and it is neither espoused nor endorsed here.

Lastly, in anthropology the sociocultural consequences of the scientific truth are as equally important as the truth itself. The current pop culture narrative where men are specially built for competition and women are specially built for reproduction helps root socioculturally prescribed and proscribed sex roles, and rigid gender rules and stereotypes, in "human nature." Expanding the dominant origins story for sex differences in height and pelvic dimensions will not just improve science but will also help rip human evolution out of the patriarchal playbook.

\section{Why are there sex differences in human stature?}

While human height varies globally, all human populations exhibit the same pattern where mean adult male height is greater than mean adult female height. In the U.S. (Figure 1), ${ }^{13}$ after nearly the same growth trajectory from 2 years of age, both males and females are roughly 62 inches $(157 \mathrm{~cm})$ tall at 13 years. After that, the female growth curve flattens to reach the average final height of about 64 inches $(163 \mathrm{~cm})$. Conversely, in males, the growth curve continues on roughly the same trajectory for at least 1.5 more years until it then flattens to reach the average final height of about 70 inches $(178 \mathrm{~cm})$. This is an additional 9\% of growth in stature compared to females. Average age of menarche in the U.S. occurs at about 13 years ${ }^{16}$ (which matches that reported in at least one small-scale subsistence society ${ }^{17}$ ).Thus, while males continue to grow in stature, females slow to a stop, and simultaneously begin monthly cycling. Females who reach menarche relatively later continue to grow-at the faster prepubertal rate until onset of menses and end up being relatively taller adults. ${ }^{18}$ The synchrony of menarche with growth deceleration and subsequent arrest is not mere coincidence. Both the menstrual cycle and skeletal growth depend on estrogen.

For males and females, long bone growth and epiphyseal closure are highly dependent on estradiol, the most important of the naturally occurring estrogens, and hereafter also referred to as "estrogen" (the literature cited also employs the terms interchangeably). ${ }^{19-21}$ Estrogen accelerates the loss of progenitor cells in the resting zone of the long bone growth plate, which causes senescence in the growth plate and results in cessation of growth. ${ }^{22-24}$ Estrogen is produced in both the ovaries and testes, where androgens are converted into estrogen by the 
enzyme aromatase. Aromatase is expressed in the growth plates, too, and so some of the hormone conversion related to bone growth is local. ${ }^{25}$ Estrogen's effects are biphasic with one level stimulating bone growth and an even higher level stimulating epiphyseal closure. ${ }^{19}$ Prepubertal females have eight times the estradiol levels of males at the same age, ${ }^{19}$ which helps explain both their earlier growth spurt (i.e. peak growth rate, which is not obvious on Figure 1 but see Bogin ${ }^{14}$ ) and earlier growth arrest compared to males. An excess of estrogen causes medically diagnosed short stature in both sexes. ${ }^{25}$ Estrogen in low doses enhances growth hormone $(\mathrm{GH})$ and IGF-1 production (the GH-IGF-1 axis) which are key to linear bone growth, ${ }^{26}$ but at high doses estrogen inhibits IGF-1. Androgens do stimulate GH, but in their absence, normal growth can occur as long as there is sufficient estrogen. ${ }^{20}$ As androgen production increases, males also reach critical levels of estradiol to stimulate the process of growth plate fusion starting around 16 years of age. ${ }^{27}$ These levels are likely to be lower than they are in females because at this older age the growth plates are more senescent and require a more brief exposure to estradiol.$^{22}$ In addition, levels of estrogen at this time are critical to bone mass maintenance, ${ }^{21}$ an important function of estrogen in all humans.

The sex difference in estradiol levels is due to its greater involvement in ovulation and menstruation than in spermatogenesis and related processes, where it is also vital. Estradiol regulates spermatogenesis by testicular Sertoli cells by both inhibiting and stimulating, in a dosedependent and temporally sensitive process. ${ }^{285}$ Aromatase activity is higher in motile as opposed to immotile sperm and was found to be significantly decreased in a population of infertile men. ${ }^{29}$ In puberty and in adulthood, excess estrogen can inhibit penile erection. ${ }^{28}$ In all humans, a delicate balance of estrogen/aromatase is as fundamental to reproduction as it is to skeletal growth. We are safe to assume that Homo sapiens ' prolific biology of reproduction is adaptive.

In addition to the effects of estrogen on stature, there may be a pubertal onset of energetic, metabolic, and nutritional costs that force a tradeoff with skeletal growth. When energy intake and physical activity are held constant, basal metabolic rate (BMR) varies significantly across the menstrual cycle, with the lowest BMR occurring approximately one week before ovulation, subsequently rising until the beginning of the next menstrual period, then decreasing at menstruation. Several studies have quantified changing energy intake across the menstrual cycle. Peak and minimum intake across the cycle differ by $359 \mathrm{kcal} /$ day $(\mathrm{n}=6) .{ }^{30}$ Ten days before menstruation, mean energy intake is approximately $500 \mathrm{kcal} /$ day higher than 10 days after $(\mathrm{n}=$ 8). ${ }^{31}$ Compared to the follicular/ovulatory phase, the luteal phase corresponds to an increased energy intake of $685 \mathrm{~kJ} /$ day (or $164 \mathrm{kcal} /$ day). ${ }^{32}$ These data point to the metabolic effects of the changing estrogen/progesterone ratios across the cycle, including the costly thickening of the endometrium. ${ }^{33-35}$ These costs may differ not just individually but across the reproductive lifespan. Reiches et al. ${ }^{36}$ described a relatively higher cost of menstruation in younger adolescents compared to older adolescents.

As this brief review of the relationship of estrogen to skeletal growth has shown, the reproductive systems of males and females differently affect a skeletal system that is shared by males and females. So, the evolutionary explanation for the existence of sex differences in human height is rooted in the origins of estrogen and its subsequent importance in all vertebrate bodies some 500 million years ago. ${ }^{37}$ Also of crucial importance are the origins of internal fertilization and viviparity. 
Great apes develop sex differences in body mass like humans do, where both sexes follow similar growth trajectories until the pubertal transition when the females stop growing and the males continue to grow for a longer period of time. ${ }^{38}$ Though levels of sex differences in body size differ between species, among the living hominids (great apes and humans) there is likely to be significant shared fundamental biology of reproduction and skeletal growth. Thus, the existence of human sex differences in stature is rooted in ancestry. It remains to be known whether there are important sex- and species-level differences in the biology of skeletal growth among hominids, and whether these could explain the differing degrees of sex differences in body size across primates, even after accounting for allometry and for estrogen productionwhich is potentially constrained by testes size and may be an important factor in the extended growth of male gorillas and orangutans. (For a discussion of how these "somatic strategies" might occur at primate puberty see ref 39.)

However, the traditional and enduring textbook explanation for sex differences in hominid body size is sexual selection ${ }^{38}$ — with large ancestral males winning competitions, which boosted their reproductive success compared to smaller males. ${ }^{40}$ Because gorillas have both intense male competition and large male bodies, the mere existence of sex differences in human body size serves as evidence of sexual selection being the driver of these differences. ${ }^{1}$

But as Plavcan ${ }^{41,42}$ has cautioned, there is not a straight-forward relationship between sexual selection and primate male body size, largely because the sorts of data that are required to investigate this relationship are difficult to obtain. It is also difficult to tease selection on male body size apart from selection on female body size through the generations, which is sometimes understood within the framework of females as the "ecological sex" ${ }^{43-45}$ Given the nutritional, energetic, metabolic, and locomotor costs of pregnancy, lactation, and mothering, ${ }^{46,47}$ there are (context-specific) limits to female body size ${ }^{48}$ perhaps leading to biology that favors reproduction over growth. ${ }^{49,50}$

Yet even within this more complete "ultimate" narrative, with selection optimizing the two sexes' skeletal growth separately, the sexual selection perspective on male height seems unnecessary. That provocative last sentence is not a claim that the sexual selection explanation is wrong or that it is implausible. But in light of what is known and still unknown about skeletal development and its relationship to the endocrinology of reproduction, suddenly there is room for skepticism about the relevance of male competition and female choice as an explanation for the existence of sex differences in stature, let alone its singular dominance of the narrative. More work is needed if sexual selection is to be held up as the explanation for why male hominids have longer bones than female hominids do.

Given the complex, shared biological systems briefly outlined above, which are intricately tied to successful reproduction and that contribute to terminal height, stature differences within adult males are probably weaker targets of selection than is assumed by sexual selection scenarios. In their recent overview of the evolution of human height variation, Stulp and Barrett ${ }^{51}$ made a similar point when they wrote that, "height itself is less important as a trait than the underlying components of growth rates and the timing of reproductive maturity that give rise to it. This 
raises the question of whether height does, in fact, carry any selective advantage independent of its links to life history."(p. 220)

Singularly upholding the male competition hypothesis for sex differences in human stature requires, for example, the demonstration that men's estradiol/aromatase production, levels, receptors, and timing are primarily due to the fitness rewards of being taller than females, or primarily due to the fitness rewards of being taller than other males. It also requires, for example, the demonstration that men's estradiol/aromatase production, levels, receptors, and timing are not primarily due to something fundamental to male gonad, genital, and gamete maturation or function, and not primarily due to shared biology with females.

Data from tracking the reproductive success of human males fails to comprehensively answer the question of why there are sex differences in human height, ${ }^{52}$ and further work of this kind, even across primates, will continue to be insufficient for elevating the sexual selection explanation for sex differences in height if it is not integrated with some insightful combination of physiological, endocrinological, developmental, and/or genetic approaches. Perspectives that assume the extended skeletal development of males is a delay in body size maturation and/or is a cost that requires a male-specific selection-based explanation must reckon with the risks that changes to the biology of male skeletal growth would also pose to the biology of male fertility. Further, investigations of these issues need not assume that a lack of sex differences in the skeleton (i.e. "monomorphy") is the biological baseline or default in all primates and, thus, that sex differences in the duration of skeletal growth or in long bone length have been directly driven apart by sexspecific sexual or natural selection on skeletal growth. Free from these assumptions, there is potential for exciting advances including, perhaps, the discovery that sexual selection does indeed play the lead role in this story.

For humans and likely other hominids, male skeletons continue to grow after females' stop because their bodies take longer to produce enough estradiol to surpass the amount that stimulates continued growth and to achieve a level that closes long bone epiphyses. As of now, no advantage to being taller or more massive is required to make sense of this phenomenon which may be largely a by-product of the adaptive reproductive biology that differs between the sexes. Dominance ${ }^{53}$ and competition may be consequences of greater height and mass, but the claim that they cause sex differences in the skeleton requires far more investigation.

\section{Why are there sex differences in human pelvic dimensions?}

On average, human female pelves have longer pubes, more laterally flaring ischial spines and tuberosities, and relatively shorter and wider sacra. Thus, they often have inlets (often measured from sacral promontory to the superior pubic symphysis), midplanes (often measured as the distance between ischial spines), and outlets (often measured from coccyx to inferior pubic symphysis or measured as the distance between ischial tuberosities) that are relatively larger in diameter than those of males ${ }^{54-56}$. These dimensions together comprise the "true pelvis" or "birth canal" which is relatively larger in females than in males. ${ }^{54}$ So, while there is geographic variation in human pelvic morphology ${ }^{57}$ and while typical female pelvic inlet shape may be "android" like males (contra traditional expectations that they be distinctly "gynecoid"58), there are consistent and patterned sex differences in human pelvic morphology pertaining to the size of the space inside the pelvic cavity. 
Fetal pelves, between seven months and birth, display sex differences that already hint at those in adults. ${ }^{59}$ Around the transition to adulthood, female pelves tend to fuse earlier than those of males at all sites. This pattern parallels the sex differences in long bone fusion. The site with the greatest sex difference in closure is the anterior epiphysis of the acetabulum which articulates with the pubis and is actively fusing between 11-16 years in females but not until ages 14-17 in males. ${ }^{59}$ Sex differences in pelvic morphology become pronounced during this stage in life. $\mathrm{LaVelle}^{60}$ found that between ages 8 and 18, female pelves expand slightly more than males' in the dimensions of the true pelvis. Some of the most conspicuous change occurs in pubis length. Likewise, Greulich and Thoms found greater transverse dimensions in developing and adult female pelves. ${ }^{61}$ Huseynov and colleagues observed, in a cross-sectional sample, that true pelvic dimensions expanded from puberty until the ages of 25-30 years, then after 40 years these dimensions diminished in magnitude. ${ }^{62}$ Whether and how the development of sex differences in the pelvis can be causally linked to intra- and inter- sex differences in the timing of the fusion of the pelvic bones remains to be determined.

Because estrogen is produced in greater amounts in female bodies and those amounts change across the life course, estrogen is the established explanation for ontogenetic changes to female pelvic anatomy as compared to that of males- ${ }^{61,63}$ This holds even for the neonatal sex differences because the last few weeks of fetal development occur while estrogen levels are highest in gestation. ${ }^{64}$ But if estrogen is a primary driver of long bone growth and fusion (as discussed above), then how does it act locally just on the bones of the pelvis and only in females?

Rodent experiments from 1929-1935 suggest that dosing a male body with estrogen "feminizes" the pelvis,${ }^{61}$ suggesting the system works on any pelvis. However, a review of skeletal biology in $2005^{26}$ reported that the stimulatory effects of estrogen on skeletal growth and maturation in humans are poorly reproduced in rodent studies. Regardless of these important issues that may complicate a comparative approach, estrogen's hypothesized localized effects on female pelves warrants deeper consideration. This is especially necessary in light of a recent study that failed to correlate within-individual levels of sex differences in the skull with that in the pelvis, suggesting that a "single systemic influence, such as hormone levels, is not solely responsible for sex differences in the size and shape of these skeletal elements." 65

The muscles of the pelvic floor, like the levator ani, the round ligament of the uterus (which is actually a smooth muscle, not a ligament), and other uterine ligaments (the pubocervical, uterosacral, and cardinal (transverse cervical) ligaments) contain estrogen receptors (ER), which suggests they are targets for estrogen. ${ }^{66-70}$

ER are absent in typical skeletal muscles like the rectus abdominis and erector spinae, ${ }^{66,67}$ supporting the hypothesis that the pelvic muscles are under special hormonal control. Pelvic floor muscles also contain ER in their connective tissue cells, which are the "glue" that fixes the muscles together and to the pelvic bones. ${ }^{67}$ The round ligament grows during pregnancy and shrinks (not slacks) after parturition, which could influence skeletal remodeling. ${ }^{71}$ The markedly earlier fusion in females, described above, of the anterior epiphysis of the acetabulum (which forms the iliopubic eminence) could be influenced by its close proximity to the deep inguinal 
ring, which transmits the round ligament. All of this suggests that the muscles and ligaments of the female pelvis influence the bones to which they are adjacent or anchored in ways that differ from other muscle- and ligament-bone interfaces, given the known effects that estrogen has on bone growth and remodeling. In addition, relaxin, which is produced by the ovary and placenta, induces the production of osteoclasts ${ }^{72}$ which are key to bone resorption and remodeling-a welldocumented phenomenon when it comes to resorption of the human, nonhuman primate, and nonhuman mammal pubis. ${ }^{73}$ Greater parity increases estrogen and relaxin exposure, which leads to the expectation that greater parity would be correlated to expanding pelvic dimensions, but at least one recent study failed to distinguish non-parous from parous female pelves. ${ }^{62}$

What is more, the volume occupied by internal female organs - in addition to the bladder and rectum housed within all pelves - may be causing the expansion of the true pelvis. The last few weeks of fetal growth show marked changes in uterus size, position, and angle of flexion. ${ }^{74}$ Neonatal uteruses are $3.5 \mathrm{~cm}$ long and $1.4 \mathrm{~cm}$ thick. ${ }^{75}$ Between the ages of $1-13$, uterine volume increases from $0.91 \mathrm{~cm}^{3}$ to $16.15 \mathrm{~cm}^{3}$, ${ }^{76}$ between ages $16-17.5$ it is $60 \mathrm{~cm}^{3}$, and between ages 2429 it is $79 \mathrm{~cm}^{3} .{ }^{77}$ The uterus begins a more rapid growth rate around 10 years of age, with the onset of puberty and during concomitant increases in luteinizing hormone (LH), follicle stimulating hormone (FSH), and estradiol. ${ }^{78}$ At this time, roughly 2-3 years before menarche, the vaginal and vulvar epithelia thicken and, along with the cervix and clitoris, they increase in size. ${ }^{78}$ Ovarian volume is $1 \mathrm{~cm}^{3}$ in the first year of life (which is larger than the second year) ${ }^{75}$, from ages 7-12.5, it increases from 1.4 to $4.9 \mathrm{~cm}^{3}$, and then from ages 16-17.5 it measures 8.9 $\mathrm{cm}^{3}{ }^{77}$ (Unlike the expanding uterus, ovarian volume from ages 24-29 is reduced, measuring 7.2 $\mathrm{cm}^{3}$.) The size of the uterus and cervix increase over a lifetime with parity. ${ }^{79}$ During the luteal phase of the menstrual cycle, when the endometrium thickens, the uterus expands to at least 1.6 its volume, likely more. ${ }^{80}$ Vaginal epithelium reaches its peak thickness mid cycle and vaginal muscle fibers thicken late in pregnancy. ${ }^{78}$ While these data were collected from small samples, datasets from different sources concur. Volumetric data on the clitoris proved elusive, but linear dimensions - like those of the bulbs measuring 3-4 cm long when flaccid and $7 \mathrm{~cm}$ when erect, and the crura measuring 5-9 cm long-are listed in ref. 81. In contrast, the only internal organ of comparable size that is specific to male pelves is the prostate which develops from $1.4 \mathrm{~cm}^{3}$ (ages 0-9) to $6.9 \mathrm{~cm}^{3}$ (ages 10-19), and to $15.3 \mathrm{~cm}^{3}$ (ages 20-29), remaining much smaller than the uterus across those age groups. ${ }^{82}$ In addition, the prostate is nestled under the bladder while the uterus and ovaries are situated higher up, within the pelvic inlet or brim, in direct line between the pubic symphysis and the sacral promontory. That is, the vagina, uterus, and ovaries are not just taking up more volume but are also, arguably, situated within a more skeletally constrained region of the pelvis compared to the prostate. Publically posted pelvic MRIs allow for visual inspection of internal pelvic anatomy and the comparison of one male and one female. ${ }^{83}$ What, if any, effects that age-related prostate enlargement may have on the male pelvis are apparently unknown, but are not predicted to mimic what is hypothesized here for developing females because of the difference in context, both in terms of age and estrogen.

The increase in size over the lifetime and the periodic expansion (during intercourse, the menstrual cycle, and pregnancy) of internal gonads and genitals may be spurring changes to the bones that form the cavity they occupy similar to the ways that organs and bones expand together elsewhere in the body. As brains and skulls develop together, signals for growth are recognized by both neural and skeletal tissues in an integrated manner. ${ }^{84}$ Growth signals may be mediated by 
tensile strain, caused by mechanical stress on the bones by the growing soft tissue. In a similar fashion, growth of the bony orbit likely responds to the development of the eye. ${ }^{85}$ Such processes are potentially occurring in the thorax, coupling the developing heart and lungs with an expanding ribcage. Habitual human swimmers provide a natural experiment for investigating this phenomenon. Documented increases in swimmers' lung volumes, especially in athletes who train intensely from childhood, are correlated with the development of physically wider chests ${ }^{86,87}$ perhaps due to the increased pressure while actively inhaling and exhaling while immersed in water. The pelvis may be no exception when it comes to the skeleton's plastic accommodation for developing soft tissue. Further, differences in the shapes of the internal skeletal spaces may vary according to the shapes of the organs within. Variation in uterine shape, existing as early as fetal development, could influence variation in pelvic proportions, and vice versa. Fetal uteruses are cylindrical, pear-shaped, heart-shaped, or hourglass-shaped. ${ }^{74}$ Amount and direction of uterine flexion, and the pace of its development, may also factor into how the pelvis develops, and vice versa. The decrease in uterine volume after peak fertility may help explain why Huseynov and colleagues ${ }^{62}$ found that older adult female pelves are less expansive.

In sum, sex differences in the dimensions of the true pelvis are influenced by localized effects of estrogen and relaxin within a system of gonads, genitals, ligaments, muscles, and bones in ways that are not fully understood. There is potential for sex differences to arise due to the plasticity of the pelvic bones to accommodate the greater volume of developmentally and functionally dynamic gonads and genitals housed within the female pelvis. As with height differences, the explanation is fundamentally rooted in the ancient origins of estrogen, internal fertilization, and pregnancy, the soft tissue differences between the sexes that evolved as a consequence, and how they affect the local skeleton differently in males and females with different hormone levels. Because sex differences in pelvic dimensions are common across primates, ${ }^{54}$ this is an ancestral condition in humans.

But, the widespread explanation for sex differences in the human pelvis is merely and simply childbirth. For example, "Females have big pelves because they give birth to big babies." 88 While intuitive, this explanation for human pelves or for other primates' is no longer a strong one-at least not in isolation as it is frequently provided.

Moffett investigated whether primates with greater cephalopelvic proportions (size of neonatal head compared to pelvic inlet) had greater pelvic sex differences and they did, but humans have even more than is explained by cephalopelvic proportions. ${ }^{54}$ That is, primates like Hylobates have similar cephalopelvic proportions to humans but exhibit smaller sex differences in the pelvis. Even chimpanzees, which have small enough neonates to fit through the male pelvis (inferred from measures published in ref. 54 and 89), still have sex differences, with female pelves being more capacious than males'.

It is possible that differences in type and magnitude of sex differences in primate pelves reflect differences in soft tissue anatomy, reproductive physiology, and effects/amounts of estrogen and relaxin and their receptors. Uterus location, size, flexion, and function could vary in important ways that impact the skeleton. Whether primate males have descended testes or not is also likely a factor. Differences across primates in clitoral anatomy as well as anatomy involved in estrus swelling could contribute to differences between species in sex differences, too. The round 
ligament grows during pregnancy and shrinks after parturition in other primates as it does in humans, ${ }^{90}$ which may contribute to their pelvic remodeling. Interestingly, rodents and lagomorphs have a different system for suspending the uterus and related organs ${ }^{91}$ and so if this is affecting their pelvic architecture, it is another reason (added to the estrogen issue mentioned above) that rat and mouse models may be inappropriate for explaining primate/human sex differences in the skeleton. When Kurki and also Fischer and Mitteroecker observed that shorter women have relatively large "obstetric" dimensions ${ }^{92,93}$ perhaps it is due to the allometry and/or conservation of size and function of soft tissues, no matter the stature. Finally, human sex differences in the pelvis could be more pronounced than expected compared to other primates' because of the more tubular or constricted construction of the hominin pelvis, and how pelves with and without internal female organs and greater estrogen exposure develop in the context of bipedalism.

A genital, gonadal, and hormonal view of the evolution of pelvic sex differences (and of the conservation of "obstetric" dimensions even in small bodied females) contrasts the traditional "ultimate" evolutionary approach that downplays developmental dynamics. A developmental perspective has less room for ideations of genetically programmed population- and speciesspecific tweaks of the space between pelvic bones in females versus males. Investigations of these issues need not assume that a lack of pelvic sex differences is the biological baseline or default and, thus, that skeletal differences have been driven apart by sex-specific selection on adult skeletal morphology. We need not assume the logic of the obstetrical dilemma hypothesis, where female pelves would be like males' if only selection for childbirth had not forced a compromise.

There is a crucial, constant function of the human female pelvis no matter the sex, age, or parity and that is to house developing, functioning organs. Female bodies and pelves contain tissues during the entire life course that stimulate pelvic bone growth and remodeling. Thus, the internal dimensions of the female pelvis are far more ovarian, uterine, clitoral, and vaginal than they are 'obstetric.' In the end, it may be that females give birth to big babies because they have big pelves.

\section{Concluding Remarks}

Investigations of sex differences in the human skeleton have faced many of the challenges in evolutionary biology that Smith described: "Some narrative explanations rely on theory-driven assumptions that may not be shared by readers... Some will not use good judgement when taking into account how underdetermination inevitably limits what can be inferred from historical data... Some will make unreasonable assumptions about what the current utility of a feature can tell us about its historical role... Some will make unreasonable assumptions that simplify the contingency of the historical situation... Some will allow coherence and simplicity in narratives to substitute for evidence." 94

Sex differences in human height and pelvic dimensions require a bigger, more complicated, and more interesting story than simply "male competition" and "childbirth." Greater estrogen results in the bones in female bodies fusing before males' leading to sex differences in adult height and mass. Female pelves expand more than males' due, potentially, to the space taken by vaginas, clitorides, uteruses, and ovaries and because of the estrogen and relaxin produced and employed 
by the tissues of the pelvic region. Generally speaking, these evolved processes are not unique to Homo sapiens. Understanding the details of the developmental biology of the skeletal and phylogenetic context, is crucial to formulating and testing evolutionary hypotheses concerning sex differences in the skeleton. With its focus on just some of the drivers of skeletal development, this essay is only one step towards expanding our evolutionary explanation for sex differences in skeletal growth.

Answers to questions about sex differences in the human skeleton should include what is increasingly known about the evolution of gonads and genitals, their growth at puberty, and their functions during skeletal maturation, sexual intercourse, the menstrual cycle, pregnancy, and menopause, as well as the sensitivities of different tissues to estrogens and androgens. The basis for the existence of sex differences deserves more attention before it will be possible to explain why humans have a certain degree of sex difference compared to other species. This may require some evolutionary research that breaks free from Mayr's proximate-ultimate convention. Laland et al. ${ }^{12}$ write that, "progress within biology demands dismantling of Mayr's identification of proximate with ontogenetic processes and ultimate with evolutionary processes." (p. 1516) The so-called "proximate" causes of sex differences in the skeleton are not only as much evolutionary ones as the "ultimate," but they hold great potential to advance investigations into how male competition and childbirth feature in the evolution of skeletal sex differences in humans. If we do not hold evolutionary hypotheses to higher standards, while also including all biology into the category of "evolution," then so many "ultimate" answers to important questions in human evolution will loom larger and longer than they deserve.

Finally, a human evolutionary narrative that expands to include the present state of knowledge about skeletal and reproductive biology and their harmonious development is not just better science. It is also less likely than the traditional scientific view to unintentionally evoke or reinforce unscientific beliefs about genetic determinism and genetic essentialism in the zeitgeist. An updated answer to why there are sex differences in the human skeleton is less likely to be interpreted to justify cultural conceptions of masculinity, femininity, and rigid binaries of sex and gender with "human nature." If we improve the scientific explanations of visible sex differences, then they are less likely to inspire unscientific beliefs about invisible ones. Fewer minds would leap illogically from 'men are taller' to 'men evolved for competition and dominance'. Likewise, fewer would observe that women are broader and conclude that 'women evolved for reproduction." As we advance science and its dissemination, fewer will mistake the human body for a blueprint for the patriarchy.

\section{Acknowledgments}

I am grateful to seven anonymous reviewers and Jason Kamilar for providing feedback that improved this paper. I am grateful to Lynn Copes and the Frank H. Netter School of Medicine for allowing me to investigate some of the anatomy described here. For what I learned, I am grateful to all I have cited. For their relevant influence, I thank Kevin Stacey, Cynthia Taylor, Sharon DeWitte, Cara Wall-Scheffler, Joan Richtsmeier, Max Lambert, T. Ryan Gregory, Anna Warrener, and Sarah Hrdy. Thanks to Anonymous for naming these pelvic ideas the VAGGINA (Virile, Active Gonads and Genitals...) Hypothesis. Any shortcomings or errors are mine and there are no conflicts of interest to declare. 


\section{References}

1. Hill AK, Bailey DH, and DA Puts. 2017. Chapter 15: Gorillas in our midst? Human sexual dimorphism and contest competition in men. In: Tibayrenc M and FJ Ayala, editors. On Human Nature: Biology, Psychology, Ethics, Politics, and Religion: Academic Press, Amsterdam, Pages 235-249

2. Dunsworth HM. 2016. Chapter 2: The 'obstetrical dilemma' unraveled. In Trevathan W and K Rosenberg, editors: Costly and Cute: Helpless infants and human evolution. Santa Fe: School for Advanced Research, p 29-50.

3. Boyd R, Silk JB. 2015. How Humans Evolved, 7th edition. New York: WW Norton \& Co.

4. Larsen CS. 2016. Essentials of Physical Anthropology. New York: WW Norton \& Co.

5. Stanford C, Allen JS, Anton SC. 2017. Biological Anthropology: The Natural History of Humankind, fourth edition. Boston: Pearson.

6. Darwin C. 1871. Descent of Man, and Selection in Relation to Sex. London: Murray.

7. Hamlin K. 2014. From Eve to Evolution: Darwin, science and women's rights in gilded age America. Chicago: University of Chicago Press.

8. Blackless M, Charuvastra A, Derryck A, Fausto-Sterling A, Lauzanne K, and E Lee. 2000. How sexually dimorphic are we? Review and Synthesis. Am J Hum Biol 12: 151-166.

9. Fausto-Sterling A. 2018. Why sex is not binary. The New York Times https://www.nytimes.com/2018/10/25/opinion/sex-biology-binary.html

10. Astorino CM. 2019. Beyond Dimorphism: Sexual Polymorphism and Research Bias in Biological Anthropology. American Anthropologist 121(2): 489-490.

11. Mayr E. 1961. Cause and effect in biology. Science 134: 1501

12. Laland KN, Sterelny K, Odling-smee J, Hoppitt W, and T Uller. 2011. Cause and effect in biology revisited: Is Mayr's proximate-ultimate dichotomy still useful? Science 334: 1512-1516.

13. Department of Health and Human Services. 2002. 2000 CDC Growth Charts for the United States: Methods and Development. Vital Health Statistics 11(246): https://www.cdc.gov/nchs/data/series/sr_11/sr11_246.pdf

14. Bogin B. 1999. Evolutionary perspective on human growth. Ann Rev Anthropol 28: 109-53. 
15. Bogin B, Varea C, Hermanussen M, and C Scheffler. 2018. Human life course biology: A centennial perspective of scholarship on the human pattern of physical growth and its place in human biocultural evolution. Am J Phys Anthropol 165: 834-854.

16. Cabrera SM, Bright GM, Frane JW, Blethen SL, and PA Lee. 2014. Age of thelarche and menarche in contemporary US females: a cross-sectional analysis. J Pediatr Endocrinol Metab 27(0): 47-51.

17. Madimenos FC, Snodgrass JJ, Liebert MA, Cepon TJ, and LS Sugiyama. 2012. Reproductive effects on skeletal health in Shuar females of Amazonian Ecuador: A life history perspective. Am J Hum Biol 24: 841-852.

18. Workman M and K Kelly. 2017. Heavier birth weight associated with taller height but not age at menarche in US females born 1991-1998. Am J Hum Biol 29(5). doi: 10.1002/ajhb.22999.

19. Cutler GB. 1997. The role of estrogen in bone growth and maturation during childhood and adolescence. J Steroid Biochem Molec Biol 61(3-6): 141-144.

20. Rogol, AD, Roemmich JN, and PA Clark. 2002. Growth at puberty. J Adolescent Health 31: 192-200.

21. Rochira V, Kara E, and C Carani. 2015. The endocrine role of estrogens on human male skeleton. Intl J Endocrinol 2015: 165215.

22. Weise, M., De-Levi, S., Barnes, K. M., Gafni, R. I., Abad, V., \& Baron, J. (2001). Effects of estrogen on growth plate senescence and epiphyseal fusion. Proceedings of the National Academy of Sciences of the United States of America, 98(12), 6871-6.

23. Singh, Divya \& Sanyal, Sabyasachi \& Naibedya, Chattopadhyay. (2010). The role of estrogen in bone growth and formation: Changes at puberty. Cell Health and Cytoskeleton. 3. 10.2147/CHC.S8916.

24. Nilsson, O., Weise, M., Landman, E. B., Meyers, J. L., Barnes, K. M., \& Baron, J. (2014). Evidence that estrogen hastens epiphyseal fusion and cessation of longitudinal bone growth by irreversibly depleting the number of resting zone progenitor cells in female rabbits. Endocrinology, 155(8), 2892-9.

25. Baron J, Sävendahl L, De Luca F, Dauber A, Phillip M, Wit JM, and O Nilsson.2015. Short and tall stature: a new paradigm emerges. Nat Rev Endocrinol 11: 735-746.

26. Nilsson O, Marino R, De Luca F, Phillip M, and J Baron.2005. Endocrine regulation of the growth plate. Horm Res 64: 157-165.

27. Katchadourian H. 1977. The Biology of Adolescence. San Francisco: Freeman. 
28. Schulster M, Bernie AM, and R Ramasamy. The role of estradiol in male reproductive function. Asian J Androl 18: 435-440.

29. Carreau S, Wolczynski S, and I Galeraud-Denis. 2010. Aromatase, oestrogens and human male reproduction. Phil Trans R Soc B 365: 1571-1579.

30. Solomon SJ, Kurzer MS, and DH Calloway. 1982. Menstrual cycle and basal metabolic rate in females. Am J Clin Nutr 36: 611-616.

31. Dalvit SP. 1981. The effect of the menstrual cycle on patterns of food intake. Am J Clin Nutr 34: 1811-15.

32. Johnson WG, Corrigan SA, Lemmon CR, Bergeon KB, and AH Crusco. 1994. Energy regulation over the menstrual cycle. Phys and Behav 65(3): 523-527.

33. Strassmann B. 1996a. Energy economy in the evolution of menstruation. Evol Anthropol 5: 157-164.

34. Strassmann B. 1996b. The evolution of endometrial cycles and menstruation. Q Rev Biol 71: $181-220$.

35. Clancy KBH. 2009. Reproductive ecology and the endometrium: Physiology, variation, and new directions. Am J Phys Anthropol 140(S49): 137-154

36. Reiches M, et al. 2013. The adolescent transition under energetic stress: Body composition tradeoffs among adolescent women in The Gambia. Evol Med Public Health 2013(1):75-85.

37. Lange IG, Hartel A, and HHD Meyer. Evolution of oestrogen functions in vertebrates. J Steroid Biochem \& Molec Biol 83: 219-226.

38. Leigh SR and BT Shea. 1995. Ontogeny and evolution of adult body size dimorphism in apes. Am J Primatol 36: 37-60.

39. Ellison P, et al. 2012. Puberty as a life history transition. Annals of Human Biology 39(5): 352-360.

40. Darwin C. 1871. Descent of Man, and Selection in Relation to Sex. London: Murray.

41. Plavcan JM. 2001. Sexual dimorphism in primate evolution. Yrbk Phys Anthropol 44:25-53.

42. Plavcan JM. 2012. Body size, size variation, and sexual size dimorphism in early Homo. Curr Anthropol 53(S6): S409-S423.

43. Slatkin M. 1984. Ecological causes of sexual dimorphism. Evolution 38(3): 622-630. 
44. Gaulin SJC and LD Sailer. 1985. Are females the ecological sex? American Anthropologist 87:111-119.

45. Gordon AD, Johnson SE, and EE Lewis. 2013. Females are the ecological sex: Sex-specific body mass ecogeography in wild sifaka populations (Propithecus spp.). Am J Phys Anthropol 151: 77-87.

46. Dunsworth HM, Warrener AW, Deacon T, Ellison PT, and H Pontzer. 2012. Metabolic hypothesis for human altriciality. Proc Natl Acad Sci USA 109 (38) 15212-15216.

47. Wall-Scheffler CM and MJ Myers. 2017. The biomechanical and energetic advantages of a mediolaterally wide pelvis in women. Anat Rec 300: 764-775.

48. Clutton-Brock TH, Harvey PH, and B Rudder. 1977. Sexual dimorphism, socionomic sex ratio and body weight in primates. Nature 269: 797-800.

49. Stearns SC. 1992. The evolution of life histories. Oxford: Oxford University Press.

50.Wood JW. 1994. Dynamics of Human Reproduction. New York: Aldine de Gruyter.

51. Stulp G and L Barrett. 2016. Evolutionary perspectives on human height variation. Biol Rev 91: 206-234.

52. Wood AR, Esko T, Yang J, Vedantam S, Pers TH, Gustafsson S, et al. 2014. Defining the role of common variation in the genomic and biological architecture of adult human height. Nat Genet 46(11): 1173-1186.

53. Stulp G, Buunk AP, Verhulst S, Pollet TV (2015) Human Height Is Positively Related to Interpersonal Dominance in Dyadic Interactions. PLoS ONE 10(2): e0117860. https://doi.org/10.1371/journal.pone.0117860

54. Moffett EA. 2017. Dimorphism in the size and shape of the birth canal across anthropoid primates. Anat Rec 300: 870-889.

55. Walrath D, Glantz M. 1996. Sexual dimorphism in the pelvic midplane and its relationship to Neandertal reproductive patterns. Am J Phys Anthropol 100(1): 89-100.

56. Walrath D. 2003. Rethinking Pelvic Typologies and the Human Birth Mechanism. Curr Anthropol 44(1): 5-31.

57. Betti L and A Manica. 2018. Human variation in the shape of the birth canal is significant and geographically structured. Proc R Soc B 285: 20181807.

58.Delprete H. 2017. Pelvic inlet shape is not as dimorphic as previously suggested. Anat Record 300: 706-715. 
59. Cunningham C, Scheurer L, and S Black. 2016. Developmental Juvenile Osteology, $2^{\text {nd }}$ Edition. Amsterdam: Academic Press.

60. LaVelle M. 1995. Natural selection and developmental sexual variation in the human pelvis. Am J Phys Anthropol 98(1):59-72.

61. Greulich WW and H Thoms. 1944. The Growth and Development of the Pelvis of Individual Females Before, During, and After Puberty. Yale J Biol Med 17(1): 91-98.8.

62. Huseynov A, Zollikofer CP, Coudyzer W, Gascho D, Kellenberger C, Hinzpeter R, and MS Ponce de León. 2016. Developmental evidence for obstetric adaptation of the human female pelvis. Proc Natl Acad Sci USA 113(9): 5227-5232.

63. Ellison PT. 2017. Endocrinology, energetics, and human life history: A synthetic model. Horm Behav 91:97-106.

64. Polese B, Gridelet V, Araklioti E, Martens H, Perrier d'Hauterive S, and V Geenen. 2014. The endocrine milieu and CD4 T-lymphocyte polarization during pregnancy. Front Endocrinol https://doi.org/10.3389/fendo.2014.00106

65. Best KC, Garvin HM, and LL Cabo. 2018. An investigation into the relationship between human cranial and pelvic sexual dimorphism. J Forensic Sci 63(4): 990-1000.

66. Smith P, Heimer G, Norgren A, and U Ulmsten. 1990. Steroid hormone receptors in pelvic muscles and ligaments in females. Gynecol Obsetet Invest 30: 27-30.

67. Smith P, Heimer G, Norgren A and U Ulmsten. 1993. Localization of steroid hormone receptors in the pelvic muscles. Eur J Obstet Gynecol Reprod Biol.50: 83-85.

68. Grigoriadis C, Hassiakos D, Bakas P, Tympa A, Panoulis C, Cretsas G, Kondi-Pafiti A, Liapis A. 2015. Effect of gonadal steroid receptors alterations on the pathophysiology of pelvic organ prolapse and urinary incontinence. Minerva Ginecologica 68(1) 37-42.

69. Lang JH, Zhu L, Sun ZJ, Chen J. 2003. Estrogen levels and estrogen receptors in patients with stress urinary incontinence and pelvic organ prolapse. International Journal of Obstetrics and Gynecology 80(1): 35-39.

70. Ewies AA, Thompson J, Al-Azzawi F. 2004. Changes in gonadal steroid receptors in the cardinal ligaments of prolapsed uteri: immunohistomorphometric data. Hum Reprod 19(7): 1622-8.

71. Smith P, Heimer G, Norgren A and U Ulmsten. 1993. The round ligament: a target organ for steroid hormones. Gynecol Endocrinol 7: 97-100.

72. Ferlin A, Pepe A, Facciolli A, Gianesello L, and C Foresta. 2010. Relaxin stimulates osteoclast differentiation and activation. Bone 504-513. 
73. Tague RG. 1988. Bone resorption of the pubis and preauricular area in humans and nonhuman mammals. Am J Phys Anthropol 76: 251-267.

74. Sulak O, Cosar F, Malas MA, Cankara N, Cetain E, and SM Tagil. 2007. Anatomical development of the fetal uterus. Early Hum Devel 83: 395-401.

75. Martins W, Leite SP, and CO Nastri. 2009. Pelvic ultrasonography in children and teenagers. Radiol Bras 42(6): http://dx.doi.org/10.1590/S0100-39842009000600014

76. Herter LD, Golendziner E, Flores JAM, Becker E, and PM Spritzer. 2002. Ovarian and uterine sonography in healthy girls between 1 and 13 years old: Correlation of findings with age and pubertal status. AJR 178: 1531-1536.

77. Cacciatore B, Apter D, Alfthan H, and U-H Stenman. 1991. Ultrasonic characteristics of the uterus and ovaries in relation to pubertal development and serum LH, FSH, and estradiol concentrations. Adolesc Pediatr Gynecol 4:15-20.

78. Farage $\mathrm{M}$ and $\mathrm{H}$ Maibach. 2006. Lifetime changes in the vulva and vagina. Arch Gynecol Obstet 273: 195-202.

79. Merz E, Miric-Tesanic D, Bahlmann F, Weber G, and S Wellek. 1996. Sonographic size of uterus and ovaries in pre- and postmenopausal females. Ultrasound Obstet Gynecol 7:38-42.

80. Piiroinen O and HL Kaihola. 1075. Uterine size measured by ultrasound during the menstrual cycle. Acta Obstet Cynec Scand 54: 247-250.

81. Mazloomdoost D and RN Pauls. 2015. A comprehensive review of the clitoris and its role in female sexual function. Sex Med Rev 3: 245-263.

82. Xia S-J, Xu X-X, Teng J-B, Xu C-X, and X-D Tang. 2002. Characteristic pattern of human prostatic growth with age. Asian J Androl 4: 269-271.

83. http://w-radiology.com/female_pelvis_mri.php; http://w-radiology.com/male_pelvis_mri.php

84. Richtsmeier JT and K Flaherty. 2013. Hand in glove: brain and skull in development and dysmorphogenesis. Acta Neuropathol 125: 469-489.

85. Moss ML and RW Young. 1960. A functional approach to craniology. Am J Phys Anthropol 18:281-92.

86. Andrew GM, Becklake MR, Guleria JS, and DV Bates. 1972. Heart and lung functions in swimmers and nonathletes during growth. J Appl Physiol 32(2): 245-251.

87. Armour J, Donnelly PM, and PTP Bye. 1993. The large lungs of elite swimmers: an increased alveolar number? Eur Respir J 6: 237-247. 
88. Tague RG. 2005. Big-bodied males help us recognize that females have big pelves. Am J Phys Anthropol 127: 392-405.

89. Schultz A. 1949. Sex differences in the pelves of primates. Am J Phys Anthropol 7(3): 401424

90. Hafez ESE and S Jaszczak. 1972. Comparative anatomy and histology of the cervix uteri in non-human primates. Primates 13(3): 297-316.

91. Van Der Schoot P. 1996. Human (and some other primates') uterine teres ligament represents a mammalian developmental novelty. Anat Rec 244: 402-415.

92. Kurki HK. 2007. Protection of obstetric dimensions in a small-bodied human sample. Am J Phys Anthropol 133(4): 1152-1165.

93. Fischer B and P Mitteroecker. 2015. Covariation between human pelvis shape, stature, and head size alleviates the obstetric dilemma. Proc Natl Acad Sci 112: 5655-5660.

94. Smith RJ. 2016. Explanations for adaptations, just-so stories, and limitations on evidence in evolutionary biology. Evol Anthropol 25: 276-287.

752

753 
754

755

756

(a)

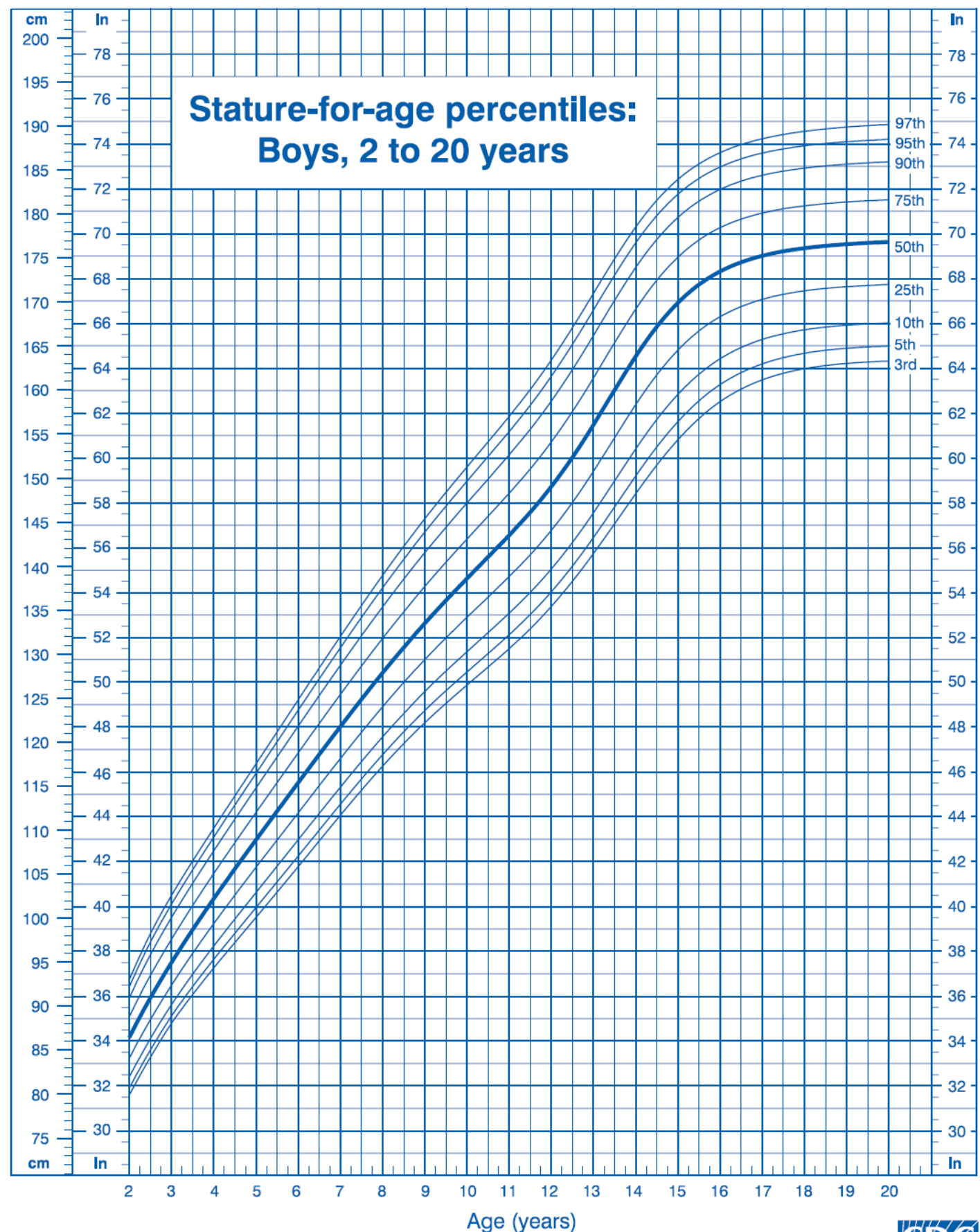

Publlshed May 30, 2000.

SOURCE: Developed by the Natlonal Center for Health Statlstlcs In collaboratlon with the National Center for Chronic Disease Prevention and Health Promotion (2000).

Figure 11. Individual growth chart 3rd, 5th, 10th, 25th, 50th, 75th, 90th, 95th, 97th percentiles, 2 to 20 years: Boys stature-for-age 


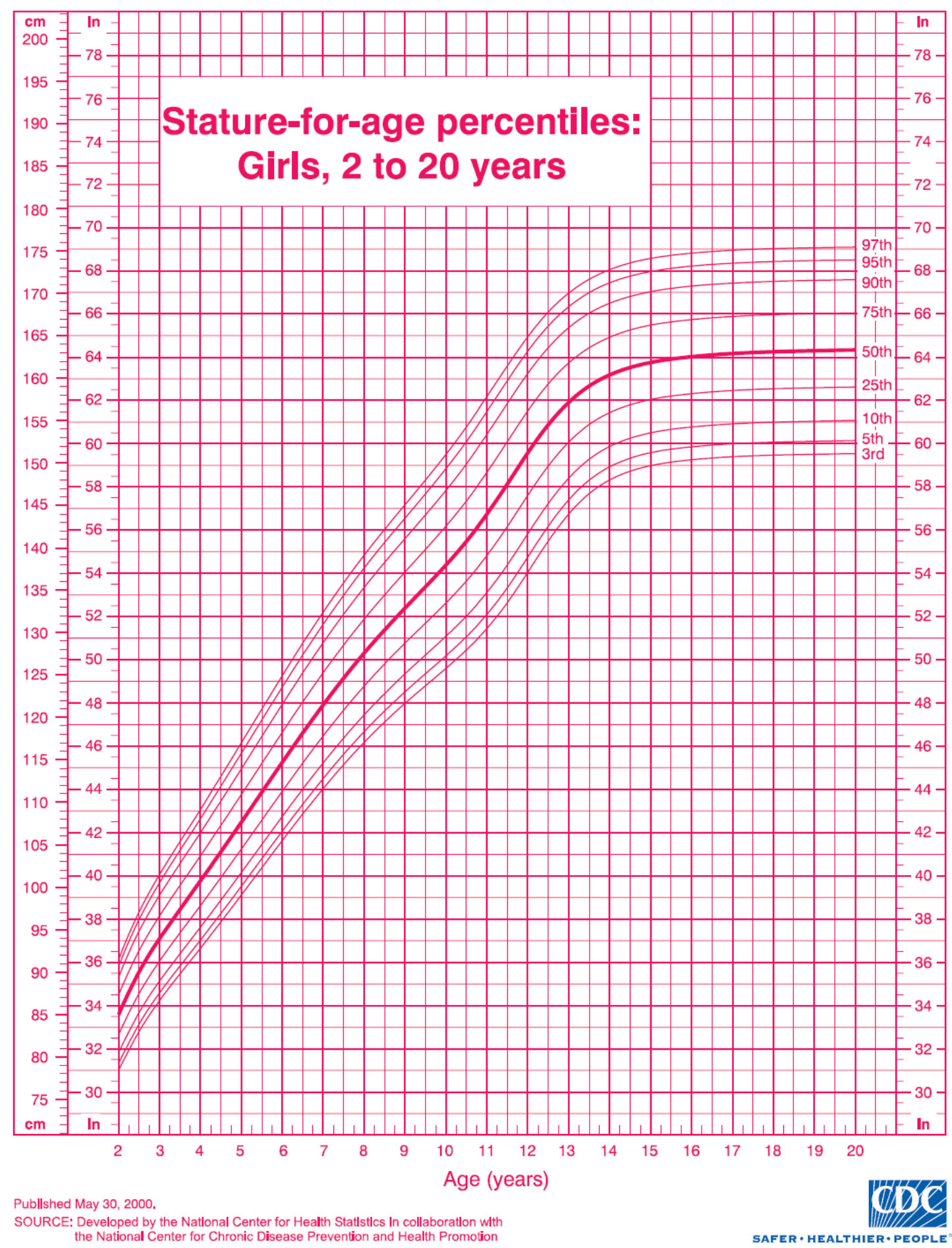

